\title{
Incidências da hermenêutica para a metodologia da pesquisa teórica em psicanálise ${ }^{1}$
}

\author{
A hermeneutical approach to the methodology \\ of theoretical research in psychoanalysis
}

\author{
Érico Bruno Viana CAMPOS \\ Nelson Ernesto COELHO JR ${ }^{2}$
}

\begin{abstract}
Resumo
O artigo traz uma breve revisão das principais abordagens hermenêuticas envolvidas na interpretação de textos e discursos a fim de delimitar a incidência dessa problemática no campo da pesquisa teórica em psicanálise. Define as diferentes formas de pesquisa em psicanálise e indica como as mudanças na compreensão da hermenêutica incidem também sobre a compreensão do estatuto epistemológico do saber psicanalítico. Apresenta e discute as propostas de metodologia de investigação teórica de Laplanche e Figueiredo. Ao concluir, indica a aproximação do método psicanalítico aplicado a textos e discursos com as perspectivas contemporâneas da hermenêutica e propõe uma abordagem própria para pesquisas de cunho histórico-conceitual e epistemológico em psicanálise.
\end{abstract}

Unitermos: Hermenêutica. Métodos de pesquisa em psicanálise. Psicanálise.

\begin{abstract}
This article aims to briefly review the major hermeneutic approaches involved with the interpretation of texts and speeches in order to establish the boundaries of the incidence of this subject on the field of psychoanalytical, theoretical research. It defines the different forms of psychoanalysis research and shows how developments in hermeneutics change the comprehension of the epistemological status of the psychoanalytical field of knowledge. It presents and discusses the methodological designs on theoretical research proposed by Laplanche and Figueiredo. Its conclusion demonstrates the approximation of the psychoanalytical method applied to texts and speeches with contemporary perspectives in hermeneutics. It also proposes a specific approach for historical-conceptual and epistemological research in the field of psychoanalysis.
\end{abstract}

Uniterms: Hermeneutics. Psychoanalysis research methods. Psychoanalysis.

A questão metodológica em pesquisas de caráter estritamente teórico costuma ser, em geral, subdimensionada. Enquanto os relatórios de pesquisa empírica necessitam de parâmetros determinados e de uma apresentação de seu delineamento, as pesquisas teóricas parecem prescindir de um instrumental de leitura. É notória a síntese do método envolvida na pesquisa teórico-conceitual em frases como "leitura

$\nabla \nabla \nabla \nabla$

1 Artigo elaborado a partir da pesquisa de doutorado em andamento, autoria de E.B.V. CAMPOS, sob orientação de N.E. COELHO JR. Apoio: Conselho Nacional de Desenvolvimento Científico e Tecnológico.

2 Universidade de São Paulo, Instituto de Psicologia, Departamento de Psicologia Experimental. Av. Prof. Mello Moraes, 1721, Bloco C, Cidade Universitária, 5508-030, São Paulo, SP, Brasil. Correspondência para/Correspondence to: E.B.V CAMPOS. E-mail: <ericobvcampos@uol.com.br>. 
crítica de textos, acompanhada de comentadores", na qual normalmente se privilegia a descrição dos textos a serem consultados e não os pressupostos da leitura a ser efetuada. É nesse sentido que se constata a presença de certa ingenuidade metodológica na interpretação dos textos, que nada mais é do que a assunção sem crítica de um referencial hermenêutico e epistemológico baseado no senso comum.

Este artigo discute questões gerais envolvidas no trabalho com a leitura de textos e discursos na pesquisa psicanalítica. O objetivo é esclarecer a problemática envolvida nesse tipo de trabalho e poder derivar uma metodologia de leitura para orientar a pesquisa histórico-conceitual em pesquisas psicanalíticas de cunho teórico. Para tanto, faz-se necessário não apenas uma problematização do que está em jogo na interpretação de textos em geral, mas também uma discussão preliminar sobre a particularidade da construção do saber em psicanálise.

Como se sabe, a discussão sobre a referência do saber psicanalítico simultaneamente ao campo da hermenêutica e ao das ciências naturais é bastante antiga. Em geral, essa polarização entre força e sentido foi utilizada para uma série de discussões sobre o fundamento epistemológico do saber psicanalítico, seja em termos de seu objeto, o inconsciente, seja em termos da especificidade de seu método.

A discussão, em geral, foi tematizada em torno da oposição estabelecida por Dilthey entre ciências explicativas e ciências compreensivas (Figueiredo, 1995). Algumas posições naturalistas foram tomadas pela psicologia do ego (Rapaport, 1982), enquanto outras, a partir da crítica pioneira da fenomenologia existencial (Binswanger, 1975; Politzer, 1998), caíram em uma perspectiva mais historicista (Schafer, 1976; Spence, 1982) ou mesmo existencialista, como a psicanálise intersubjetivista ou relacional americana (Gomes, 2007; Storolow, Orange \& Atwood, 2001). Outras, contudo, procuraram manter a distância entre o campo da psicanálise e o da hermenêutica, ou mesmo das ciências humanas em geral. O argumento, muitas vezes, é de que o método psicanalítico é mais do que a hermenêutica. O próprio Ricoeur (1977), em seu clássico ensaio, mostrou como, embora a dimensão do sentido fosse constitutiva do campo psicanalítico, o sentido não podia prescindir de uma dimensão de força, própria ao campo dos afetos e da pulsão. Esse tipo de posicionamento acabou sendo preponderante de tal forma que atualmente se considera ultrapassada a tentativa de articulação entre hermenêutica e psicanálise.

Os autores desse artigo, contudo, partem de uma perspectiva diferente com relação à hermenêutica, além de terem um objetivo distinto. Nosso recurso à discussão hermenêutica está relacionado à grande inflexão linguístico-pragmática que sofreu a filosofia contemporânea (Oliveira, 1996), deixando a problemática epistemológica em segundo plano, passando a discutir as racionalidades regionais constituídas por cada campo de saber (Mezan, 2002), além de suas perspectivas éticas (Figueiredo, 1996). Nesse sentido, como veremos, a contribuição hermenêutica poderá ser tomada em uma perspectiva renovada.

Quanto ao objetivo, a intenção do presente artigo não está em defender o recurso à hermenêutica como forma alternativa de abordagem do objeto psicanalítico, mas sim em utilizá-la para fundamentar um método de interpretação de textos de temática psicanalítica. Por isso, inclusive, trata-se de uma proposta referente somente às pesquisas teóricas em psicanálise, como definiremos a seguir.

\section{Modos de pesquisa no campo psicanalítico}

O campo psicanalítico possui aspectos em comum com o conhecimento científico, como coesão interna, comunicabilidade, verificabilidade e cumulatividade. Essas noções, contudo, devem ser entendidas na particularidade da produção de conhecimento em psicanálise, em especial na configuração do campo psicanalítico como um espaço necessariamente dispersivo em que as formações teóricas não são redutíveis entre si, o que coloca empecilhos a uma redução da psicanálise a noções epistemológicas como a de paradigma (Mezan, 1998).

A pesquisa em psicanálise se efetiva em diversos níveis de investigação. Devem-se levar em consideração algumas distinções clássicas sobre o campo de pesquisa em psicanálise, de forma que se possa inserir a presente discussão nesse contexto.

A produção de conhecimento em psicanálise pressupõe sua operacionalização no âmbito de um setting transferencial, onde o inconsciente pode emergir. 
Dessa forma, a verdadeira pesquisa em psicanálise é aquela que emerge da clínica psicanalítica. Essa posição clássica é a defendida, em sua versão mais ortodoxa, por Freud nas suas propostas de ensino de psicanálise na universidade, segundo as quais este deveria ser concebido com o intuito de divulgação das proposições psicanalíticas e de forma dogmático-crítica (Mezan, 1998).

Evidentemente, o saber psicanalítico não é uma mônada fechada sobre si mesma e articulações muito profícuas foram estabelecidas entre a psicanálise e as demais ciências. Em particular, muito já foi discutido sobre as diferenças e especificidades da forma de produção de conhecimento que é específica do método psicanalítico em relação aos modos tradicionais da pesquisa acadêmica. De qualquer forma, a especificidade da pesquisa que emerge da clínica é o ponto essencial da teorização psicanalítica. Nesse sentido, podemos definir um primeiro tipo de pesquisa psicanalítica, a qual pode ser propriamente denominada de pesquisa em psicanálise (Garcia-Roza, 1994) ou de pesquisa clínica (Mezan, 1994). Nessa perspectiva, a teoria em psicanálise é, fundamentalmente, um trabalho de pensamento, abstração e elaboração que ocorre depois da escuta analítica e a partir dela, constituindo o cerne do saber psicanalítico.

Em contraposição a essa primeira vertente de investigação dos processos psíquicos por meio do método psicanalítico, encontram-se as pesquisas sobre psicanálise (Garcia-Roza, 1994). É nessa proposta que se inserem as pesquisas propriamente acadêmicas. Dizem respeito à investigação da história das ideias psicanalíticas, quer seja no plano exclusivamente histórico-conceitual - as articulações e desenvolvimentos conceituais de uma teoria psicanalítica -, quer seja no plano mais epistemológico - a inserção de teorias psicanalíticas no contexto da produção de conhecimento em geral (Mezan, 1994).

Mezan diferencia, ainda, a pesquisa de caráter aplicado, que diz respeito à articulação da compreensão psicanalítica com a cultura. Essa ideia de uma "aplicação" da teoria psicanalítica, contudo, não deve ser entendida nos mesmos moldes da distinção entre pesquisa básica e pesquisa aplicada, já que a teorização em psicanálise emerge do seu próprio método e nele se efetiva. Outro ponto é que há algumas distinções entre as posições desses dois autores. Garcia-Roza é mais restritivo, considerando o lugar da pesquisa eminentemente como o de uma pesquisa em psicanálise, enquanto a leitura sistemática caberia aos comentadores e se inseriria no âmbito de uma pesquisa epistemológica e não psicanalítica. Já Mezan é mais flexível, reconhecendo o lugar de uma pesquisa teórica de caráter-histórico conceitual e mesmo epistemológico como complemento à indagação do campo clínico.

Considerando essa breve demarcação do que poderíamos chamar de delineamentos de pesquisa no campo da psicanálise, cabe agora considerar as especificidades da forma de pesquisa teórica em psicanálise a partir do recurso à hermenêutica.

\section{Hermenêutica como recurso metodológico}

Pode-se esquematizar o campo da hermenêutica como constituído por duas polaridades ideais: a da interpretação reprodutiva e a da interpretação criativa, ou seja, aquela que procura resgatar um suposto sentido intrínseco da obra e aquela que é a produção de um sentido novo a partir da subjetividade do leitor (Figueiredo, 1994). O primeiro polo é o mais clássico, tomando como pressuposto e critério de validade a manutenção do distanciamento entre o sujeito e o objeto de leitura, enquanto o segundo é mais atual e se aproximará das perspectivas contemporâneas de compreensão da racionalidade intrínseca aos campos de saber. Faremos um breve retrospecto dessa discussão no campo restrito da hermenêutica para, posteriormente, relacionarmos essas posições ao campo da psicanálise.

A vertente da interpretação reprodutiva origina-se na hermenêutica moderna com Scheleiermacher (1999) e Dilthey (2003), com derivações para os trabalhos de Hirsh Jr. (1967), Betti (1992) e Eco (1993).

A metodologia hermenêutica de interpretação de textos de Schleiermacher (1999) estava claramente orientada pelo ideal exegético de reconstrução do sentido original do texto, fundamentando-a em um conceito geral de compreensão. Sua proposta é elaborar uma teoria da compreensão que possa fornecer, ao mesmo tempo, as regras de procedimento interpretativo e as razões desses procedimentos. A problemática da compreensão surge da ideia de que a tarefa hermenêutica se dá a partir do estranhamento diante de um 
texto, ou seja, de que a necessidade de interpretar surge de uma distância entre o texto e o leitor, em que aquele não é plenamente compreensível e assimilável, mas, também, não é radicalmente outro.

A questão da interpretação dos sentidos ganha maior abrangência a partir de Dilthey (2003). Esse autor afirmou a separação entre o campo das Ciências do Espírito/Humanas e o das Ciências Naturais, baseada na distinção entre o compreender e o explicar. Assim, a compreensão passou a desempenhar o papel de atributo essencial para as ciências humanas de tal modo que a hermenêutica passa de mero método para fundamento epistemológico.

A hermenêutica moderna traz consigo o projeto de instrumentar a reconstrução da intenção autoral por meio de uma metodologia assentada em uma série de pressupostos, tais como a identidade atemporal de uma intenção autoral, a não contradição entre a intenção do autor e do texto e assim por diante. Por mais que sejam admitidas as dificuldades da situação hermenêutica sua contingência histórica, a inevitabilidade do círculo hermenêutico etc. - , há a crença na identidade da intenção autoral subjacente e independente dessas dificuldades. Essa concepção constituirá o polo mais tradicional da discussão sobre a hermenêutica.

Nessa vertente, Betti (1992) preocupa-se em traçar uma metodologia antirrelativista a partir do pressuposto da universalidade antropológica do espírito e de suas formas representativas como modo de superação do psicologismo, entendendo a verdade da interpretação como a correspondência entre a representação alcançada e o modelo ideal de significação. 0 conhecimento interpretativo, por sua vez, é entendido como a reconstrução objetiva da subjetividade por meio do caminho inverso da criação original. Trata-se de traçar, através de um metodologismo e tecnicismo hermenêuticos, os parâmetros e as condições de reconstrução do sentido original através de cânones interpretativos (Betti, 1992). O que distingue a proposta desse autor é seu enfoque transcendental: o método hermenêutico não encontra a intenção subjetiva do autor, mas sua forma significativa ideal, que é universal. O que está em jogo é a reconstituição da forma significativa transcendental comum à experiência.

Hirsh Jr. (1967) se insere na mesma tradição da 250 hermenêutica como interpretação reprodutiva. Distin- gue entre o nível empírico ou vivencial do texto - sua significância - e o nível transcendental da intenção autoral - seu sentido objetivo. O sentido é entendido como uma intenção transcendente do autor, referida a um campo de objetos intencionais também transcendentais. O caráter intersubjetivo no compartilhamento de sentido é o que permite a possibilidade de um acesso ao nível transcendental da intenção autoral. $\mathrm{O}$ autor distingue uma pluralidade de horizontes referidos à obra como princípios para a interpretação objetiva: 1) horizontes externos à obra: é o contexto de recepção alheio à intenção autoral; 2) horizontes internos da obra: é o nível intratextual, pautado pela coerência e identidade; 3) horizontes externos da obra: é o contexto de objetos intencionais a que a obra está ligado. A atividade interpretativa deve distinguir esses planos de abertura.

A posição de Eco (1993) sobre os limites da interpretação e o perigo da superinterpretação também se encaixa nessa perspectiva. Sua preocupação é o perigo do pleno subjetivismo, cuja expressão mais radical é de que a obra será nova a cada leitura, não havendo o que se possa chamar de um sentido original ou mesmo compartilhado. Seu argumento é apoiado em três conceitos: 1 a intenção do autor; 2 a intenção da obra; 3 a intenção do intérprete (Eco, 1993). O autor define a intenção da obra como uma "estratégia semiótica" (Eco, 1993, p.76), desempenhando o papel de uma fonte de significados que não se resume à intenção subjetiva do autor, mas que restringe a liberdade de uma intenção qualquer do intérprete. Em acordo com a tradição contemporânea, rejeita a validade do propósito empírico do autor como critério de validade de uma interpretação. Coloca-se, ainda, contra o subjetivismo do autor e do intérprete. Defende uma dialética entre o texto e seu leitor, uma vez que a intenção textual só pode ser inferida a partir de sua atualização na leitura do intérprete. Contudo, o leitor empírico não é o verdadeiro objeto intencional do texto. O texto é um dispositivo que visa à produção de seu leitor-modelo através da sua atualização na leitura do intérprete. Por sua vez, a intencionalidade do intérprete deve visar à construção de um autor-modelo ideal que acabaria por coincidir com a intenção da obra. É nessa dialética de aproximações sucessivas de objetos ideais que se desenrolaria o processo interpretativo. 
As concepções dos autores acima discutidos dizem respeito ao eixo mais tradicional da problemática hermenêutica, aquele que considera a interpretação como reprodução do sentido. Embora tenhamos diferenças significativas entre eles, pode-se notar a manutenção de um pressuposto ideal na definição do sentido atribuído ao objeto em sua apreensão pela atividade do intérprete. O método interpretativo consistiria na depuração das ambiguidades e aspectos contingentes, eliminando a diferença, a ruptura, o conflito e a subjetividade como obstáculos à compreensão. Quer seja em uma perspectiva mais psicológica, quer seja em um transcendentalismo apriorístico ou mesmo na configuração de contextos intersubjetivos ideais, o que está presente é a ideia de um reencontro do intérprete com o objeto, que é apreendido e concebido por meio de parâmetros como totalidade, unidade, coerência, harmonia e assim por diante.

Passemos, agora, para a ideia da interpretação como criação de sentido. O problema nessa perspectiva é como, reconhecendo a prevalência da subjetividade, garantir certo rigor na interpretação. Essa empreitada passa, necessariamente, por uma concepção da interpretação a partir de um fundo do qual emerge a figura da obra, ou seja, da interpretação como uma atividade de construção e desconstrução de contextos. Os contextos, nesse caso, são tanto externos - inserção histórico-cultural - quanto internos - a própria rede de articulação teórico-conceitual - e estão interrelacionados. É importante ressaltar que esses contextos não são passíveis de reconstrução ideal, mas são sempre dinâmicos e contingentes. Tem-se, assim, a concepção de uma interpretação que responda à obra a partir da experiência que esta propicia ao leitor. Nesse sentido, a interpretação eficaz se dá não pela sua capacidade de conservação, mas, sobretudo, pela emergência de novas configurações que propiciam, conforme o termo utilizado por Figueiredo, a"fabricação do estranho"(Figueiredo, 1994, p.21).

Uma primeira concepção de interpretação como procedimento de contrução/reconstrução de contextos é a de extração fenomenológica-existencial defendida por Gadamer (1997) a partir da ampliação do campo da hermenêutica efetuada pela ontologia de Heidegger.

Partindo do problema hermenêutico subjacente ao conhecimento, Gadamer (1997) afirma a necessidade de reconhecimento da positividade das características históricas do objeto das ciências do espírito. Assim, os contextos e a tradição precisam ser afirmados como condição e não obstáculos ao conhecimento. Nesse sentido, a compreensão histórica do mundo necessariamente se dá em um horizonte. É preciso, portanto, reconhecer os significados e preconceitos envolvidos na compreensão prévia do mundo, ou seja, a alteridade e a tradição precisam ser reconhecidas no processo interpretativo. A situação hermenêutica constitui-se como a imersão na tradição que se deseja compreender. Esses pressupostos devem ser entendidos em seu duplo caráter de condição de possibilidade (preconceitos legítimos) e barreiras (preconceitos arbitrários). A compreensão é invariavelmente mediada por esses horizontes tradicionais, os quais atuam antecipando o sentido e como suposição de saber em seu contato com o texto. Tanto o intérprete como a tradição estão inseridos em seus próprios horizontes. A condição e a tarefa da interpretação estão no alargamento do horizonte próprio na integração do outro. Essa fusão de horizontes (Bleicher, 1992) é a ideia reguladora do processo interpretativo, entendida como um processo constante, uma vez que ambos os horizontes se configuram no tempo histórico.

A compreensão, portanto, deve ser entendida na e pela historicidade. Seu caráter é dialógico no sentido de que o processo de fusão de horizontes obedece a uma lógica de perguntas e respostas endereçadas do intérprete ao texto e vice-versa. O texto é entendido como um substrato que é atualizado na compreensão, o que implica uma concepção de interpretação como criação e coautoria. É preciso deixar-se contrariar e transformar pelo texto, ao mesmo tempo em que sua tradição é atualizada. Essa atividade de interpretação seria, necessariamente, interminável, uma vez que a alteridade do texto e do intérprete não é passível de equacionamento. Sua validade seria dada de forma teleológica por meio da ideia reguladora de fusão de horizontes entre texto e leitor. Assim, mais do que a submissão à autoridade de uma verdade já dada, o que se observa é a afirmação da dimensão ética subjacente ao processo interpretativo, na qual o fundamental é a alteridade entre autor e intérprete como motor da cocriação de sentido. O problema hermenêutico, assim, passa a ser, primeiramente, com relação ao conhecimento. 
Concepções como essas abrem espaço para a afirmação da necessidade de reconhecimento das questões iniciais do intérprete como condição e ponto de partida para uma interpretação. Esse ponto é essencial para um trabalho de pesquisa teórica: o sentido não está dado em si no texto ou no passado de sua tradição, mas será função, também, da configuração de seu domínio de pesquisa atual. Essa constatação certamente coloca em novas bases a ideia de uma revisão de literatura, pois reconhece a dimensão histórica e contextual na produção do conhecimento.

A crítica a uma epistemologia fundacionista pode ser encontrada também no neopragmatismo de Rorty (1993). Esse autor está inserido na tradição do pragmatismo americano (Peirce, James e Dewey) e alinhado às concepções de Wittgenstein sobre os jogos de linguagem. Em linguística e semiótica, a pragmática diz respeito à dimensão de uso da linguagem, ao sentido implícito dos discursos e seus efeitos na comunicação. Dessa abordagem, deriva-se uma teoria dos atos de linguagem. A linguagem não comunica representações para além de si, mas é, ela mesma, um ato expressivo e constitutivo de sentido. A palavra não é veículo de um significado transcendente, mas o próprio ato de significação. Não há, assim, nada para além da linguagem; não há um fundamento ontológico ou metafísico subjacente. A linguagem é a ferramenta com a qual e por meio da qual se desdobra a experiência humana: o sujeito é constituído na e pela linguagem. A ideia de uma "verdade" passa a ser remetida a sua eficácia ou efeito.

As teses pragmáticas têm aspectos antiessencialistas comuns ao pensamento heideggeriano-gadameriano. A diferença é que em Heidegger a crítica ao essencialismo recai em uma analítica do existir - Dasein -, enquanto no pragmatismo ela constitui uma teoria da linguagem como instrumento e ato. Nesse sentido, acaba por implicar, em suas interpretações mais rasteiras, uma ideologia relativística em que as teorias são pensadas como ferramentas para o uso indiscriminado, desde que tragam as finalidades desejadas.

A ideia central na concepção de Rorty (1993) é que interpretar textos nada mais é do que usá-los, ou seja, as descrições de um texto são função de seu uso instrumental a serviço de objetivos, desconsiderando a

252 fidelidade ao objeto descrito. Nessa perspectiva, a leitura e a escrita são usos de linguagem, com finalidades persuasivas, em função de um conjunto de outros textos e leituras. Assim, concepções como intenção do autor e sentido objetivo da obra não passariam de ficção, havendo apenas a intenção do intérprete. O interpretar, assim, não é nada além de contextualizar sem que se conceba o resultado pautado por parâmetros externos aos propósitos do sujeito.

Apesar de seu antiessencialismo e da crítica às dualidades metafísicas em geral, nota-se uma patente anulação da alteridade nas concepções neopragmáticas. O texto, nessa perspectiva, não é outro para o intérprete; não cria tensões e transformações. Pelo contrário, a ideia de uso com finalidades persuasivas do intérprete simplesmente exclui a ideia de alteridade. No máximo, o intérprete usa o texto para ampliar seu sistema de crenças - seu contexto - e transformar a si mesmo, mas "não'sai de si'na direção de um 'além de si"' (Figueiredo, 1999, p.14).

Apesar das diferenças apontadas, tanto na concepção pragmática quanto na gadameriana, percebe-se a recusa de uma validade transcendental. Possuem como ponto comum a definição da validade a partir da regulação entre contexto e texto, quer seja de forma mais defensiva ao sistema de crenças (pragmática), quer seja de forma mais dialógica (gadameriana). Há, ainda, a manutenção do lugar do ideal, apesar de sua reformulação em uma dimensão contextual. Assim, por mais que os avanços de Gadamer e Rorty ressignifiquem o problema hermenêutico, percebe-se, ainda, certa filiação a uma ontologia da unidade. Apesar de essas concepções não tomarem as "teses" de um texto como transcendentais e atemporais, mas reavaliáveis em função dos contextos históricos contemporâneos à sua produção ou leitura, há lugar para a unidade do sentido. Essa unidade se impõe sobre a diferença, mesmo que vários sentidos possam ser reconstruídos em diferentes leituras e que esse sentido não seja referido a uma intenção autoral.

Esse tipo de concepção de interpretação implica aquilo que Figueiredo (1999) denominou de leituras sistemáticas e próximas em oposição a leituras próximas e desconstrutivas. Nas primeiras, o contingente e o acidental não são necessariamente ignorados, mas interpretados a partir de um suposto movimento intrínseco à obra ou à sua contextualização em uma tradição. $\mathrm{O}$ 
ambíguo aqui revela uma contradição de teses ou um ponto de inflexão que é redimensionado em função da evolução das teses da obra ou do seu horizonte externo. Sua validade é dada não só por uma concepção pragmática estrita, mas pela sua fecundidade heurística e pelo rigor de uma verdade consensual. Nesse sentido, uma boa leitura sistemática não deve se fechar ao espanto nem à passividade inerentes à sua interpretação, muito menos recair em ilusões totalizantes ou dogmatizantes.

Uma leitura próxima desconstrutiva (Figueiredo, 1999), por sua vez, parte de um patamar mais radical. Trata-se de pensar uma leitura que seja próxima sem se fechar (close) em uma suposta unidade. Para tanto, é necessário admitir um fato até então ignorado ou subdimensionado na tradição hermenêutica, a saber, de que o texto seja outro para si mesmo. Até então, o que se observa é a consideração da alteridade entre os horizontes do autor e do intérprete, ou da obra em relação à sua tradição, mas sempre se pressupôs uma unidade ideal de sentido, mesmo que entendida em uma relatividade histórica. A metodologia desconstrutiva, desenvolvida, entre outros, por Derrida (2001), vai afirmar a alteridade radical no seio do próprio horizonte interno da obra.

A leitura desconstrutiva constitui-se, assim, na terceira concepção hermenêutica, que parte de procedimentos de construção e reconstrução de contextos. É, também, a mais radical delas. Seu fundamento é a afirmação da precedência e prevalência da marca diferencial sobre a essência. Entende a diferença como fator constituinte dos sentidos; a identidade se constituindo sobre esse campo descentrado, ambíguo e móvel. Em suma, o lugar do ideal é aqui abolido: em vez de uma ontologia essencialista, o que se tem é uma ontologia da diferença.

Essa perspectiva se alimenta do retórico e do contingente para evidenciar os limites das teses centrais, procurando o movimento atético do texto, evidenciando as ilusões dogmatizantes de uma identidade de sentido, em uma incessante transgressão. A desconstrução não intenciona qualquer transcendência, mas a própria heterogeneidade dos elementos do texto, implodindo-o para evidenciar seus próprios sentidos marginais.

O procedimento desconstrutivo é bastante metódico uma vez que está preocupado com as articu- lações internas do texto. Compartilha com as tradições contextualizantes a crítica à linguagem referencial e a uma historicidade linear, mas, contudo, insiste no"compromisso com a obra literária" como aspecto ético fundamental da leitura desconstrutivista (Miller, 1995) no sentido de que volta sua atenção para a trama intratextual. Percebe-se que, a partir do momento em que a coerência do horizonte interno da obra perde sua certeza, o problema das articulações internas do texto ganha um novo estatuto. O procedimento desconstrutivo, assim, é um mergulho no texto, porém pautado por uma lógica não-identitária ou suplementar.

A concepção de suplementaridade diz respeito ao caráter diferencial das teses de um texto ou dos conceitos de uma teoria. As perspectivas essencialistas, ao afirmarem a precedência da essência sobre a diferença, entendem que uma tese se constitui como um em si, para depois vir a se contrapor a sua antítese. Esse é o campo dos dualismos, em que impera a contraposição entre teses opostas e distintas, as quais, no máximo, podem ser entendidas como complementares. Essa complementaridade, por sua vez, tenderia a ser compreendida em uma temporalidade dialética em que a oposição dirige-se à anulação da diferença em uma nova síntese. A ambiguidade, aqui, é produtora de tensões, mas o ideal identitário é o objetivo final.

A ideia de um suplemento de origem, por sua vez, transcende a lógica identitária. A lógica suplementar age entrelaçando os sentidos e mostrando como suas condições de possibilidade remetem ao seu outro irredutível, a sua própria impossibilidade. Nesse sentido, a ambiguidade não é pacificada ou contida, mas sustentada, mostrando como o que é representado se articula ao que está na sombra.

Ao tomar o horizonte interno do texto como campo privilegiado de investigação de ambiguidades inalienáveis, a leitura desconstrutiva redimensiona o problema da intertextualidade. A ideia é que o texto é outro para si mesmo, nutrindo-se dos fios que ligam suas polaridades intrínsecas e os enxertos de elementos externos. É dessa trama discursiva em que o outro se insere como elemento ao mesmo tempo hostil e positivante, na qual o texto é simultaneamente hóspede e hospedeiro (Miller, 1995), que emergem os movimentos de significação. 
A metodologia desconstrutiva traz de novidade a ideia de que o texto é constituído de ambiguidades suplementares, desdobrando-se sobre uma série de articulações intra e intertextuais criadoras de tensão. Um texto, nessa perspectiva, não é um horizonte instrínseco fechado e unidimensional, mas a verdadeira arena em que as tradições da obra e do leitor se digladiam. Assim, a desconstrução é o recurso por excelência de investigação da dimensão de alteridade que resiste à sistematização, uma verdadeira tática de guerrilha ao desejo totalizante de conhecimento. Nesse sentido, coloca-se na amplitude extrema dos movimentos de um processo de teorização.

Se a leitura próxima nos alerta para o movimento dialógico do texto com a sua tradição, a desconstrução traz esse diálogo para o âmbito do próprio movimento constitutivo das teses e antíteses de um texto. Mais que isso, alerta para a necessária articulação suplementar que une um conceito ao seu negativo. Assim, uma leitura sistemática e uma desconstrutiva estarão unidas entre si pela suplementaridade, como hospedeiro e parasita. Essa constatação é importante para um trabalho de leitura sistemática dos conceitos de um autor e alerta para a atenção à ambiguidade como fator constitutivo dos movimentos do pensamento e para a ilusão de uma unidade de teses em uma obra.

\section{Incidência da hermenêutica na epistemologia da psicanálise}

Como indicamos na introdução deste artigo, a hermenêutica não constitui apenas um referencial metodológico para a interpretação de textos e discursos. O desenvolvimento da problemática hermenêutica tem um impacto importante no campo da filosofia contemporânea, além de ter implicações diretas para o estatuto do saber psicanalítico. Evidentemente, apresentar toda essa discussão foge aos propósitos deste artigo. Além das indicações gerais de nossa introdução, sugerimos ao leitor que consulte as referências para conhecer melhor o alcance da virada linguístico-pragmática na compreensão contemporânea da constituição dos campos de saber.

A discussão sobre as perspectivas hermenêuticas e sua incidência no campo psicanalítico é bem resumida lizaremos como referência para nossa própria discussão. Partindo do debate contemporâneo sobre a concepção da psicanálise como uma atividade estritamente narrativa ou de criação de sentidos (Storolow et al., 2001), o autor propõe a esquematização do campo hermenêutico em duas perspectivas - a tradicional, ou hermenêutica 1, e a reformulada, ou hermenêutica 2 (Phillips, 1991). Como vimos, essa posição, que acompanha a discussão da epistemologia da psicanálise desde o seu início, parte da ambiguidade entre a pretensão científica da metapsicologia em oposição ao seu método, que seria hermenêutico e implicaria uma dimensão existencial.

O autor retoma o argumento de vários autores dessa tradição com o intuito de esclarecer dois pontos. O primeiro deles é que os autores oriundos do campo das ciências humanas e da hermenêutica reconhecem que a psicanálise não pode ser reduzida apenas a sua dimensão hermenêutica, já que a noção de um campo de forças está igualmente presente, o que justificaria um modelo "misto" de psicanálise: parte hermenêutica, parte ciência natural (Phillips, 1991). Esse argumento remonta ao trabalho de Ricoeur, que defende não só a dimensão hermenêutica - que cobriria a compreensão do sentido dos sintomas -, mas, também, uma dimensão de força - que cobriria a compreensão dos fenômenos de distorção e resistência - na construção do desejo (Ricoeur, 1977).

O segundo aspecto, também fundamental, é que essa oposição se insere na problemática que emerge da hermenêutica tradicional. Ou seja, trata-se da hermenêutica entendida como a busca de compreensão do sentido da expressão, clarificando-o por meio de um método. É essa compreensão que polariza o debate epistemológico na oposição entre um método hermenêutico e um empírico, tal como exemplificado em Dilthey. Assim, a contraposição entre força e sentido como essências que não se misturam, subsumidas a abordagens epistemológicas distintas e opostas, só se sustenta a partir de uma visão moderna de filosofia da ciência e em uma concepção estritamente metodológica de hermenêutica, denominada por Phillips (1991) hermenêutica 1.

Uma visão renovada da hermenêutica tem origem no deslocamento da problemática hermenêutica do método para a ontologia, o que está em estreita 
ligação com os avanços contemporâneos na filosofia da ciência e na epistemologia. Essa mudança de concepção do problema hermenêutico tem origem na ontologia heideggeriana e no trabalho de Gadamer. A essa tradição filosófica de cunho fenomenológico-existencial, vieram se somar os enfoques neopragmáticos e as abordagens desconstrutivistas.

São os avanços teóricos trazidos por essas perspectivas que configuram a hermenêutica 2. A hermenêutica é entendida como aquilo que emerge da falha do projeto da modernidade. Em seu sentido ampliado, surge como um discurso que transita no conflito da incomensurabilidade dos discursos, o solo de onde parte a compreensão após a derrocada da crença em um único referencial epistemológico (Phillips, 1991). Nesse sentido, transcende as distinções clássicas, próprias da hermenêutica 1, entre ciências da natureza e ciências humanas. Ou seja, para além das dicotomias entre força e sentido ou explicação e compreensão, a hermenêutica 2 circunscreveria o próprio meio de construção de conhecimentos por meio de uma compreensão renovada de verdade. Em outras palavras, a segunda hermenêutica diz respeito ao contexto que emerge a partir do que autores têm chamando de virada linguístico-pragmática na filosofia contemporânea (Oliveira, 1996).

Em um texto recente sobre a epistemologia da psicanálise, Mezan (2002) retoma a problemática da especificidade do saber psicanalítico em sua discussão com a epistemologia. Em consonância com as perspectivas epistemológicas mais contemporâneas, notadamente a epistemologia francesa de Bachelard e Lebrun, afirma que "uma disciplina se emancipa e se torna autônoma quando define seu campo, seus métodos, sua problemática própria" (Mezan, 2002, p.437), de tal modo que cada ciência é responsável pela construção de sua própria racionalidade. Esse ponto é fundamental, pois recoloca o problema da epistemologia para além de sua concepção unívoca de verdade. Em maior consonância com a virada linguístico-pragmática, essa concepção epistemológica "fraca" lida com a ideia de racionalidades regionais, próprias de cada campo de saber. Assim, uma investigação epistemológica passa pela descrição e pela análise do sistema de enunciados de um determinado campo de saber, mostrando como ele funciona e como constrói seu horizonte de conheci- mento. Nesse sentido, não se trata mais de referir o saber da psicanálise - ou de qualquer outro conhecimento - a um determinado crivo epistemológico que garanta a verdade de um método ou de um enunciado teórico.

Nesse sentido renovado, a epistemologia passa a ser um instrumento de análise da coerência interna de um campo de saber mais próximo dos expedientes hermenêuticos de análise. Essa abordagem coloca em um novo patamar a discussão sobre o lugar da metapsicologia no saber psicanalítico, uma vez que a retira da posição de uma pretensa sistematização teórica de caráter cientificista, além de recolocar em novas bases dicotomias clássicas, como a oposição entre força e sentido. Do mesmo modo, permite uma articulação mais consistente entre a hermenêutica e um método de leitura e escuta propriamente psicanalíticos.

\section{Por uma hermenêutica psicanalítica}

A discussão precedente sobre as perspectivas hermenêuticas não é interessante apenas pelo seu auxílio em compreender a inserção da metapsicologia no debate "epistemológico"contemporâneo. É, também, essencial para compreendermos a derivação de um instrumental de leitura de textos e suas relações com a especificidade do saber psicanalítico.

Diante disso, propomos marcar a aproximação entre a metodologia desconstrutiva e alguns aspectos da formação de conceitos em psicanálise.

A perspectiva desconstrutiva traz derivações importantes para o trabalho de pesquisa com textos psicanalíticos. Isso se dá não apenas pela afirmação de que uma teorização necessariamente se desenvolve sobre seus suplementos de origem, o que certamente traz uma nova perspectiva para as pretensões lineares de leitura, mas, também, pela aproximação da lógica da suplementaridade na formação de conceitos com a própria noção de inconsciente. Alguns autores encontrarão no modo de teorização psicanalítica uma aproximação com a lógica desconstrutiva, uma vez que o texto freudiano está marcado pelo movimento retórico do "não apenas, mas em vez disso" (Miller, 1995, p.69), o que denotaria a remissão dos conceitos - no caso a ideia de construção - a contrapontos suplementares sem que um centro identitário possa ser, de fato, isolado. 
Leituras desconstrutivas de textos psicanalíticos têm sido efetivadas por diferentes autores contemporâneos. $O$ movimento da desconstrução tem origem na crítica literária e propõe a análise da alteridade interna do texto. Seu principal propagador na psicanálise é o francês Derrida (2001), encontrando ressonâncias tanto no meio psicanalítico anglo-saxão (Bass, 1996) quanto no meio brasileiro, além da própria psicanálise francesa. Nesse aspecto, o trabalho já citado e comentado de Figueiredo (1999) sobre a intertextualidade entre Freud e Ferenczi na elaboração do conceito de pulsão de morte constitui um verdadeiro modelo de aplicação desse tipo de estratégia de leitura na literatura nacional.

Já a caracterização de uma metodologia especificamente psicanalítica de leitura foi preconizada por Laplanche (1988; 1998). Seus trabalhos iniciais de interpretação de textos freudianos tinham uma perspectiva mais dialógica e desconstrutiva, expressa em sua concepção de "fazer o texto trabalhar" por meio da "utilização de conceitos analíticos como chave de uma nova hermenêutica" (Laplanche, 1998, p.10). É essa perspectiva de leitura histórica, interpretativa e problematizante do texto freudiano que nos interessará em particular. Essa concepção hermenêutica afirma a possibilidade de ler os escritos psicanalíticos por um método psicanalítico. Isso significa não uma interpretação das fantasias de seus autores, mas a utilização do próprio método psicanalítico como instrumento de leitura.

Esse método está baseado em um princípio de análise igualitária, que é o aplainamento ou desmantelamento dos enunciados textuais a partir de uma atenção igualmente flutuante. Com isso, crescem de importância a absurdidade dos detalhes, os esquecimentos e deslocamentos de um texto. A ideia é destituir os"remanejamentos egoicos" (Laplanche, 1988) da doutrina freudiana, desmontando os conceitos da obra. Nessa abordagem, a noção de desenvolvimento histórico é problematizada. Em vez de um desenvolvimento linear, observam-se as contingências da articulação de uma problemática cuja temporalidade está próxima daquela própria da psicanálise: repetição, retorno do recalcado, ressignificação a posteriori etc. A ideia de uma estrutura do pensamento freudiano, assim, só pode ser entendida no sentido de um equilíbrio dinâmico entre polaridades.

A ideia fundamental de percorrer a obra em to256 dos os sentidos, sem nada omitir ou privilegiar a priori, possibilitando a emergência de uma problemática que não se resolve linearmente e que, pelo contrário, constrói um campo intermediário de exigências teóricas (Laplanche, 1998) é um procedimento hermenêutico bastante interessante para a interpretação de textos psicanalíticos. Podemos afirmar que esse tipo de estratégia está em consonância com a discussão contemporânea sobre a incidência da hermenêutica para a compreensão da construção dos saberes.

A metodologia desconstrutiva, por sua vez, em sua ênfase na ambiguidade e alteridade intrínsecas ao texto, aproxima-se da perspectiva psicanalítica. O método psicanalítico caracteriza-se pela escuta diferenciada ao estranho, identificando, no que é acessório, a irrupção dos sentidos inconscientes da trama de símbolos trazida pelo paciente por meio da atenção flutuante. Aproxima-se ainda mais da perspectiva laplanchiana, que possibilita justamente a transposição dessa estratégia para a interpretação de textos e a compreensão histórico-conceitual e epistemológica da psicanálise.

Embora essas propostas sejam interessantes e permitam aproximações, é necessário, contudo, marcar algumas diferenças. Enquanto a análise desconstrutiva não visa nenhum fim para além de si mesmo e toma esse tipo de compromisso teleológico como uma ilusão essencialista, uma hermenêutica psicanalítica como a de Laplanche guarda lugar para um sentido final no movimento do pensamento do autor. A noção de uma exigência de teorização que emerge das contradições e ambiguidades de um texto recoloca o lugar de um ideal regulador. É evidente que estamos aqui longe da concepção de um sentido inequívoco latente no texto. Trata-se de uma temporalidade em espiral e, ao mesmo tempo, polarizada em opostos suplementares. Essas tensões criam linhas de força que possibilitam a concatenação de um desenvolvimento teórico que, contudo, não pode ter a pretensão de verdade absoluta, uma vez que essa é histórica e contextualizada.

De qualquer forma, a aproximação entre as perspectivas desconstrutiva e laplanchiana para a pesquisa teórica em psicanálise, tanto de cunho histórico-conceitual quanto epistemológico, mostra-se uma estratégia interessante e consistente de investigação que tem sido, inclusive, desenvolvida em algumas publicações recentes no meio psicanalítico nacional (Campos, 2004; 2006; Ribeiro, 2000). 


\section{Considerações Finais}

Com a indicação dos desdobramentos da problemática hermenêutica para o campo da psicanálise, chegamos ao final deste artigo. Esperamos ter deixado claro como os movimentos inerentes ao campo da hermenêutica contribuíram para uma fundamentação epistemológica em que cabem a especificidade do conhecimento psicanalítico e procedimentos inerentes ao seu método. Esse percurso, por sua vez, possibilitou também delimitar uma abordagem metodológica de investigação de textos psicanalíticos apoiada nas concepções desconstrucionistas e laplanchianas. Dessa forma, pudemos, a partir da discussão sobre a incidência da hermenêutica na compreensão da psicanálise como campo de saber, apresentar um método de pesquisa próprio para investigações teóricas em psicanálise.

\section{Referências}

Bass, A. (1996). A história de um erro de tradução e o movimento psicanalítico. In P. Ottoni (Org.), A prática da diferença (pp.55-90). Campinas: Unicamp.

Betti, E. (1992). A hermenêutica como metodologia geral das Geisteswissenschaften. In J. Bleicher (Org.), Hermenêutica contemporânea (pp.77-131). Lisboa: Edições 70.

Binswanger, L. (1975). Being-in-the-world: collected papers of Ludwig Binswanger. London: Souvenir Press.

Bleicher, J. (Org.) (1992). Hermenêutica contemporânea. Lisboa: Edições 70.

Campos, E. B. V. (2004). Figuras da representaçãonaemergência da primeira tópica freudiana. Dissertação de mestrado não-publicada, Universidade de São Paulo.

Campos, E. B. V. (2006). O jogo das alteridades: a ética em Freud. Anais do $2^{\circ}$ Congresso Brasileiro de Psicologia: Ciência e Profissão, São Paulo. Recuperado em fevereiro 6, 2008, disponível em http://www.cienciaeprofissao.com.br/ anais/detalhe.cfm?idTrabalho=1698

Derrida, J. (2001). Mal de arquivo: uma impressão freudiana. Rio de Janeiro: Relume-Dumará.

Dilthey, W. (2003). O Surgimento da hermenêutica. Numen: Revista de Estudos e Pesquisa da Religião, 7 (2): 11-32.

Eco, U. (1993). Interpretação e superinterpretação. São Paulo: Martins Fontes.

Figueiredo, L. C. (1994). A fabricação do estranho: notas sobre uma hermenêutica "negativa". Boletim de Novidades da Pulsional, 57, 17-22.

Figueiredo, L. C. (1995). Matrizes do pensamento psicológico (3a ed.) Petrópolis: Vozes.

Figueiredo, L. C. (1996) Revisitando as psicologias: da epistemologia à ética das práticas e discursos psicológicos. Petrópolis: Vozes.
Figueiredo, L. C. (1999). Palavras cruzadas entre Freud e Ferenczi. São Paulo: Escuta.

Gadamer, H.-G. (1997). Verdade e método: traços fundamentais de uma hermenêutica filosófica. Petrópolis: Vozes.

Garcia-Roza, L. A. (1994). Pesquisa de tipo teórico. Psicanálise e Universidade, 1, 9-32.

Gomes, P. (2007). Psicanálise relacional contemporânea: uma nova maneira de trabalhar em psicanálise. Revista Brasileira de Psicanálise, 41 (4): 113-123.

Hirsh Jr., E. D. (1967). Validity in interpretation. New Haven: Yale University Press.

Laplanche, J. (1988). Interpretar com Freud. In J. Laplanche. Teoria da sedução generalizada e outros ensaios (pp.21-32). Porto Alegre: Artes Médicas.

Laplanche, J. (1998). Problemáticas I: a angústia (3a ed). São Paulo: Martins Fontes.

Mezan, R. (1994). Pesquisa teórica em psicanálise. Psicanálise e Universidade, 2, p.51-76.

Mezan, R. (1998). O que significa pesquisa em psicanálise? In R. Mezan. A sombra de Dom Juan e outros ensaios (pp.85-118). São Paulo: Companhia das Letras.

Mezan, R. (2002). Sobre a epistemologia da psicanálise. In R. Mezan. Interfaces da psicanálise (pp.436-519). São Paulo: Companhia das Letras.

Miller, J. H. (1995). A ética da leitura: ensaios 1979-1989. Rio de Janeiro: Imago.

Oliveira, M. A. (1996). Reviravolta lingüístico-pragmática na filosofia contemporânea. São Paulo: Loyola.

Phillips, J. (1991). Hermeneutics in psychoanalysis: review and reconsideration. Pychoanalysis and Contemporary Thought, 14 (3): 371-424.

Politzer, G. (1998). Crítica dos fundamentos da psicologia: a psicologia e a psicanálise. Piracicaba: Unimep.

Rapaport, D. (1982). A estrutura da teoria psicanalítica: uma tentativa de sistematização. São Paulo: Perspectiva.

Ribeiro, P. C. (2000). O problema da identificação em Freud: recalcamento da identificação feminina primária. São Paulo: Escuta.

Ricoeur, P. (1977). Da interpretação: ensaio sobre Freud. Rio de Janeiro: Imago.

Rorty, R. (1993). A trajetória do pragmatisa. In U. Eco (Org.), Interpretação e superinterpretação (pp.105-128). São Paulo: Martins Fontes.

Schafer, R. (1976). A new language for psychoanalysis. New Haven: Yale University Press.

Schleiermacher, F. D. E. (1999). Hermenêutica: arte e técnica da interpretação. Petrópolis: Vozes.

Spence, D. (1982). Narrative truth and historical truth: meaning and interpretation in psychoanalysis. New York: Norton.

Storolow, R. D., Orange, D. M., \& Atwood, G. E. (2001). Horizontes do mundo da experiência: uma alternativa pós-cartesiana ao inconsciente freudiano. Revista Brasileira de Psicanálise, 35 (1), 45-61.

Recebido em: 14/4/2008

Versão final reapresentada em: 6/3/2009

Aprovado em: 1/4/2009 